\title{
Effects of Spirulina platensis supplementation on lipid profile in HIV-infected antiretroviral naïve patients in Yaounde - Cameroon: a randomized trial study
}

Marthe-Elise Ngo-Matip ${ }^{1 *}$, Constant Anatole Pieme², Marcel Azabji-Kenfack², Prosper Cabral Nya Biapa ${ }^{3}$, Nkenfack Germaine ${ }^{3}$, Englert Heike ${ }^{4}$, Bruno Moukette Moukette ${ }^{2}$, Korosky Emmanuel ${ }^{5}$, Stefanini Philippe ${ }^{6}$, Carl Moses Mbofung ${ }^{1}$ and Jeanne Yonkeu Ngogang ${ }^{2}$

\begin{abstract}
Background: Cardiovascular diseases (CVD) and metabolic alterations are among the majors public health concern that have been reported in people living with HIV infections. Factors contributing to cardio metabolic syndrome in HIV include body fat distribution, dyslipidemia, insulin resistance, cardiovascular dysfunction and inflammation. The aim of the study was to determine the effect of Spirulina platensis (Cyanobacteriaceae) supplementation versus local diet on lipid profile in HIV-infected antiretroviral-naive patients.

Methods: A prospective single-blind, randomized, multicentre study was conducted from February 2010 to December 2012. A total of 320 HIV antiretroviral-naive patients were screened and 169 were recruited in this study. Patients were randomized and received either Spirulina supplementation combined with local diet $(n=82)$ or local diet only $(n=87)$. Age, weight, body mass index (BMI), lipid profile, CD4 count, and local food intake variables were assessed on three separate occasions (three, six and twelve months).

Results: An average age of the patients was $35.6 \pm 9$ years. The majority of participants were female $67.1 \%$. Regarding the lipid profile, there is a significant increase in HDL-cholesterol and a significant decrease in total cholesterol, LDL-cholesterol and triglycerides in the group of patients who consumed Spirulina platensis. A change in the atherogenic index defined by the ratio $\mathrm{CT} / \mathrm{HDL}-\mathrm{C}$ substitutable by $\mathrm{LDL}-\mathrm{C} / \mathrm{HDL}-\mathrm{C}$ and the TC/HDL decreased significantly from 10.83 at baseline to 2.22 after 12 months $(p=0.21$ and $p<0.0001)$ in the patients taking Spirulina.
\end{abstract}

Conclusions: Nutritional supplementation with Spirulina combined with a quantitative and qualitative balanced diet for at least six months can retard an exposition to lipid abnormalities in HIV-infected antiretroviral-naive patients. Further studies are recommended on a large group of people not infected with HIV and exposed to cardiovascular risk factors.

Keywords: Spirulina platensis, Atherosclerosis, HIV+ antiretroviral naïve, Lipid profile

\footnotetext{
* Correspondence: m_matipde@yahoo.de

1 National Institute of Agro-Industrial Sciences, University of Ngaoundere,

POBOX 455, Ngaoundere, Cameroun

Full list of author information is available at the end of the article
} 


\section{Background}

Patients with human immunodeficiency virus (HIV) infection are at increased risk of developing coronary heart disease (CHD) although traditional risk factors contribute to elevate the risk [1]. There is growing evidence that HIVinfected individual develop more risk of coronary heart disease (CHD) than healthy patient. Studies showed that the incidence of the CHD risk of HIV-infected patient varied from different countries [2]. Recent reports have shown that cardiovascular deaths accounted for $6.5 \%$ of total deaths in a large observational cohort of HIV-infected patients from Europe and North America, for $8 \%$ of deaths among HIV-infected people in France, and for $15 \%$ of deaths in a North American HIV outpatient study [3-6]. In Sub-Saharan Africa, one of the several Public Health problems is HIV/AIDS [7]. Since the early days of the HIV epidemic, the effects of HIV disease on serum lipids have been described [8]. Cardiovascular diseases have been the leading cause of morbidity and mortality in the general population [3] and have now also been identified as a major cause of death in people with HIV/AID [9].

Cardiovascular diseases (CVD) have emerged as a major public health problem and impose an escalating burden on the health care system in Cameroon. A study in this country between 1992 and 1997 ranked coronary artery disease eighth among the CVDs registered with a prevalence of 1.53 percent [10,11]. A study conducted between November 2009 and November 2011, in a population of 8,389 adults and 706 children consulted in the St. Elizabeth Catholic General Hospital of Shisong, Cameroon showed the increase of incidence with $41.5 \%$ diagnosed for Hypertension; $29.6 \%$ for congestive heart failure, $12.2 \%$ for arrhythmia [12]. Data from the same study demonstrated and confirmed previous works which showed that cardiac involvements in human immunodeficiency virus (HIV) infection, with cor pulmonale and pericarditis contribute to over $20 \%$ of cases of heart failure [12,13]. In Cameroon, about $5.5 \%$ of the population are infected of HIV mostly women and individuals aged between 15 and 49 years are most commonly identified [14]. Studies reported an increase of triglycerides (TG), total cholesterol (TC), low density lipoprotein cholesterol (LDL-C), and decrease of high density lipoprotein cholesterol (HDL-C) has raised concern about increased risk of atherogenesis and atherosclerotic vascular disease [15-18]. These abnormalities are common in adults infected with the Human Immunodeficiency Virus (HIV) [19]. The HIV infection itself has been shown to cause changes in glucose and lipid metabololism [20,21]. Few studies have been carried out in Cameroon on disturbances in lipid metabolism and nutritional deficiency in HIV-infected patients [22]. In spite of the relatively high prevalence of HIV in this country, little is known about cardiovascular disease (CVD) among HIV-infected antiretroviral naive persons [8]. There are numerous evidences that nutritional deficiency (ND) is highly prevalent in HIV-infected patients, especially among patients from Sub Saharan Africa [23]. The risk factors of Nutritional Deficiency in HIV infected patients are: a precarious social situation, poor adherence to diet modification and comorbidities. Very few researches on the effects of dietary supplements combined with an appropriate balance diet and medical follow up of HIV infected patients have been published. The dietary supplements strategy could be in the long period slow down the progression of metabolic complications among HIV-infected antiretroviral naïve patients. Due to the difficulties to access to a balanced diet, a supplementation of a safety cyanobacterium such as S. platensis in the diet or in the treatment of HIV patients naives or under antiretroviral drugs is necessary [24]. This blue green alga is used as a food supplement all over the world [25,26]. Studies have demonstrated its beneficial effects on human health on glucose, lipid metabolism and blood pressure through its full content in antioxidant combined with vitamin A, B12, E, proteins and mineral salt and also in building immunity of patients with HIV infection and multiple cardiovascular risk factors [24,27-29]. It also was reported that the protein $\mathrm{C}$-phycocyanin present in $S$. platentis play a crucial role in the decrease of hypercholesterolemic action [30,31].

The determination of lipid parameters is not required during follow-up of HIV-infected patients. Although disturbances in lipid metabolism have been found in HIVinfected patients, no study has yet been carried out to determine whether these disturbances are caused by the treatment or by other factors. However, a previous study in Cameroon has shown its interest in severely infected people living with HIV [24].

The present study was designed to assess the potential effect of S. platensis supplementation on the progression of atherogenetic dyslipidaemia among HIV-Infected antiretroviral naïve patients.

\section{Methods}

\section{Nutritional composition of S. platensis}

Dry S. platensis powder was obtained from a local farm of spirulina in Central Africa. It was kindly donated by a Cameroonian Association of Knowledge-Attitudes-Practices "KAP" in Yaounde-Cameroon. The Table 1 shows it's the composition (g per 100 grams of powder). The total protein was determined by using the Kjeldahl method [32]. The total lipids, dietary fiber and ash were determined using the standard methods of AFNOR [33]. The total sugar was determined by using standard methods of Cerning and Guilbot [34] while the minerals salt were described by using the AOAC [32]. 
Table 1 Composition of freeze-dried powder of Spirulina platensis intake in our study

\begin{tabular}{lcc}
\hline Composition & g/100 of dry mass (\%) & $\begin{array}{c}\text { Energetic values } \\
\text { (kilo calories) }\end{array}$ \\
\hline Macronutrients: & 61.81 & 258.36 \\
Total Proteins (g) & 16.06 & 144.54 \\
Lipids (g) & 12.36 & 51.66 \\
Carbohydrates (g) & 9.77 & \\
AHK (g) & 88.75 & \\
Dry mass & 02.26 & \\
Dietary fiber (g) & & \\
Micronutrients & 0.28 \\
Calcium (mg) & 0.93 \\
Magnesium (mg) & 14.40 \\
Potassium (mg) & 1.96 \\
Na + (mg) & 90.75 \\
Total Nitrogen & 21.98 \\
Iron (mg) & 7.81 \\
pH
\end{tabular}

The analysis of the freeze-dried spirulina powder sample obtained from the Institute of Medical and Medicinal Plants (IMMP) (Yaounde-Cameroon).

\section{Criteria of selection of population of study}

We carried out a longitudinal study in a randomized cohort from January 2011 to February 2012. Patients aged between 18 - 65 years, HIV-infected antiretroviral naïve to treatment and with CD4 count $\geq 400$ cells $/ \mu \mathrm{L}$ were eligible. Patients who shown their CD4 drop to $\leq 400$ cells $/ \mu \mathrm{L}$ during the follow-up were excluded. Participants were also required not to be on lipid modifying therapies at their enrolment. Informed consent was obtained from every subject prior to the participation. The study was approved by the Cameroon National Ethic Committee under the following reference number: 123/CNE/SE/2011, Cameroon. The subjects were recruited by the medical file of the Day Care Clinic of Central Hospital of Yaounde (CHY) and of the Biyem-Assi District Hospital. Investigation and intervention were carried out at the Etoug-Ebe Health Center.

\section{Selection, randomization, treatment allocation and follow up} Selected participants (169 subjects) were included in the study among 116 women and 53 men. Of the 169 subjects, we allocated 87 subjects to the control group (first group) and 82 subjects to the intervention group (second group). HIV infected patients were selected after checking patients files for CD4 counts above 400 cells/ $\mu \mathrm{l}$ who were ARV naïve to treatment (Figure 1). The two groups were well matched with respect to age, sex, and CD4 cells counts. At the entrance of the study, patients had been fasting for at least eight hours overnight.

The patients of the first group were advised to take a fresh local balance diet while patients of the second group were asked to add S. platensis in their local diet during the first six months. The $S$. platensis was given in package of powder doses of 10 grams per day. The next six months were for the follow-up without S. platensis powder. Anthropometric measurements (weight, height, BMI) were done at baseline, after six and twelve months for the two groups.

All anthropometric measurements were done with the same electronic weighing device (SECA QUALITY SEAL GERMANY). The BMI was calculated using Quetelet's formula; Weight/height ${ }^{2}$ and expressed as $\mathrm{Kg} / \mathrm{m}^{2}$ to the nearest one decimal place.

Subjects were treated "as usual" "usual care" treatment in Cameroon means patients are subjected to practitioner's choice of therapy. This consists of routine fasting blood sugar level and lipid profile control after six months. To monitor these parameters, two types of standardized questionnaire for demographic characteristics, clinical, quality of live (alcohol consumption, tabac, physical activities and dietary habits), and a three day diet intake data was filled by the subjects at the baseline, during and at the end of the trial.

\section{Dietary records}

Food intake was recorded using a predesigned "three days" questionnaire. Subjects had to document time, quantity and quality of food or beverage consumed. They were instructed to: (1) document all consumed foods and beverages in as much detail as possible, (2) to weigh foods (or to estimate doses, if weighing was not possible in some situations), (3) to document food or beverage intake immediately after consumption and (4) not to change usual eating habits. Data analysis was performed using the nutrition software EBISpro2011, version 8.0 for Windows. In analyzing the eating records, nutrients were studied in relation to the dietary reference intakes (DRI) (EBISpro 2011) [35]. The DRI utilized corresponds to the age group and sex. The nutrients evaluated in this study include are posted in Table 2. Deficiency was defined as a concentration below the reference interval: Proteins $57.1 \mathrm{~g}$, Iron 10 mg, Zinc 10 mg, Calcium 1000 mg, Potassium 3500 mg, Magnesium 350 mg, Cholesterol 300 mg.

\section{Determination of biochemical parameters}

The blood samples were obtained through patients in two tubes of $4 \mathrm{~mL}$, one dry and the content Ethylene diamino Tetracetic Acid (EDTA). The dry tube was used to determine the lipid profil using coloring method with Kits (Human). The LDLC-C levels were determined using method of Friedewald et al. [36]. The following definitions were used for dyslipidemia: Total cholesterol $\geq 240$ $\mathrm{mg} / \mathrm{dl}$, Low-density lipoprotein cholesterol $\geq 130 \mathrm{mg} / \mathrm{dl}$, Triglycerides $\geq 150 \mathrm{mg} / \mathrm{dl}$, and High-density lipoprotein cholesterol < $40 \mathrm{mg} / \mathrm{dl}$. TC/HDL-C and LDLC/HDLC 


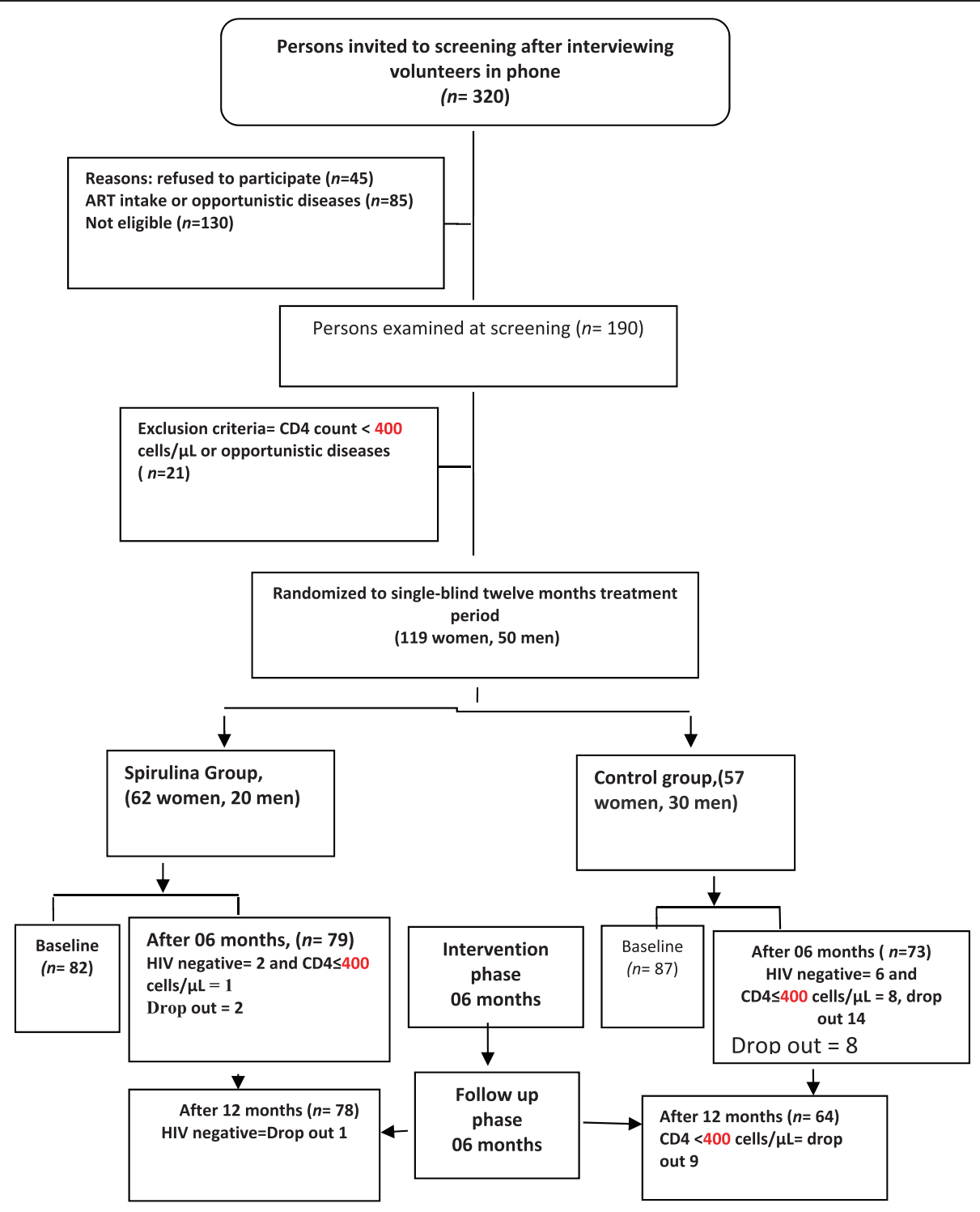

Figure 1 Flow chart describing progress of participants through the Spirulina platensis supplementation trial.

ratios were used to calculate the atherogenicity index. When the ratio TC/HDL-C $>4.85$ and LDL-C/HDLC > 3.55 than the atherogenic index is statistically significant.

Fasting blood sugars were determined using « ULTRA ONE TOUCH" glucometer. The level of glycemia higher than $\geq 110 \mathrm{mg} / \mathrm{dL}$ were identified like cardiovascular risk factors.

The Flow Cytometry (FACS CALIBUR II Machine) was used for the determination of CD4 lymphocytes count in all patients. Values were expressed as cells $/ \mu \mathrm{L}$.

\section{Statistical analysis}

Each experiment was carried out in triplicate. Results were considered significant at $p$-value less than 0.05. Data are presented as mean \pm standard deviation or as percentage.
Chi-square was performed to determine the significance of differences in the prevalence of dyslipidemia in both groups. Student's $t$-test version 3.3.2 was used to compare the lipid parameters of both groups. The statistical SPSS program (version 16.0) was used for all the analysis.

\section{Results}

\section{Dietary records}

The results of the nutrients intake of the population the two groups can be classified in two groups which include macronutrients and mineral (Table 2). The results showed the increase of protein intake and the decrease of the cholesterol level with significant difference during the last 6 months of the study to the group of population who add S. platensis to their local diet. In contrary to this group, 
Table 2 Micronutrients intake of the HIV-ARV naïve population before and after spirulina supplementation

\begin{tabular}{|c|c|c|c|c|c|}
\hline Variables & Ctrol/Spi & Period & Patients received local balance diet & $\begin{array}{l}\text { Patients received spirulina combined } \\
\text { with a local balance diet }\end{array}$ & $p$-value \\
\hline \multirow[t]{3}{*}{ Proteins (g) } & $87 / 82$ & T0 & $60.51 \pm 16.39$ & $48.03 \pm 8.85$ & $<0.001$ \\
\hline & $79 / 80$ & T6 & $62.61 \pm 14.12$ & $66.03 \pm 9.3$ & 0.10 \\
\hline & $66 / 79$ & $\mathrm{~T} 12$ & $60.28 \pm 13.52$ & $72.77 \pm 7.3$ & $<0.001$ \\
\hline \multirow[t]{3}{*}{ Iron (mg) } & $87 / 82$ & T0 & $12.03 \pm 1.12$ & $12.85 \pm 2.64$ & $<0.01$ \\
\hline & $79 / 80$ & T6 & $11.86 \pm 1.30$ & $16.04 \pm 1.20$ & $<0.001$ \\
\hline & $66 / 79$ & $\mathrm{~T} 12$ & $11.80 \pm 1.14$ & $14.67 \pm 3.75$ & $<0.001$ \\
\hline \multirow[t]{3}{*}{ Zinc (mg) } & $87 / 82$ & T0 & $81 \pm 6.35$ & $70 \pm 4.50$ & $<0.001$ \\
\hline & $79 / 80$ & T6 & $6.36 \pm 2.67$ & $5.79 \pm 1.70$ & 0.15 \\
\hline & $66 / 79$ & $\mathrm{~T} 12$ & $4.28 \pm 3.16$ & $6.92 \pm 1.53$ & $<0.001$ \\
\hline \multirow[t]{3}{*}{ Calcium mg } & $87 / 82$ & T0 & $487.09 \pm 194.58$ & $666.18 \pm 680.75$ & $<0.02$ \\
\hline & $80 / 79$ & $T_{6}$ & $509.60 \pm 248.11$ & $1339.90 \pm 303.37$ & $<0.001$ \\
\hline & $79 / 66$ & $\mathrm{~T}_{12}$ & $510.87 \pm 220.48$ & $943.85 \pm 308.39$ & $<0.001$ \\
\hline \multirow[t]{3}{*}{ Potassium (mg) } & $87 / 82$ & T0 & $1148,48 \pm 2,00$ & $766,57 \pm 2,40$ & $<0.01$ \\
\hline & $79 / 80$ & T6 & $2306 \pm 733.53$ & $4555 \pm 798.93$ & $<0.001$ \\
\hline & $66 / 79$ & $\mathrm{~T} 12$ & $2593 \pm 112.44$ & $3241 \pm 709.83$ & $<0.001$ \\
\hline \multirow[t]{3}{*}{ Magnesium (mg) } & $87 / 82$ & T0 & $223.23 \pm 114.60$ & $250.10 \pm 91.99$ & 0.11 \\
\hline & $79 / 80$ & T6 & $231.61 \pm 88.78$ & $428.44 \pm 78.5$ & $<0.001$ \\
\hline & $66 / 79$ & $\mathrm{~T} 12$ & $251.21 \pm 143.00$ & $288.00 \pm 80.70$ & 0.07 \\
\hline \multirow[t]{3}{*}{ Cholesterol (mg) } & $87 / 82$ & T0 & $379.37 \pm 83.24$ & $464.54 \pm 160,74$ & $<0.001$ \\
\hline & $79 / 80$ & T6 & $402.77 \pm 66.29$ & $216.32 \pm 100.50$ & $<0.001$ \\
\hline & $66 / 79$ & $\mathrm{~T} 12$ & $413.88 \pm 56.05$ & $292.67 \pm 55.54$ & $<0.001$ \\
\hline
\end{tabular}

Mean values \pm SD, Ctrl: Control, Spi: Spirulina group T0: initial period, T6: Six months, T12: Twelve months Mean values \pm SD. $p<0.01:$ Significant difference between the group.

we found the increase of cholesterol level to the other group and the variation of protein (Table 2). Regarding the micronutrients intake, the Iron, Calcium and Magnesium increase significantly during the trial in the population who supplemented S. platensis in their diet (Table 2).

\section{Characteristics of population studied}

The sample population of the study at the baseline was 169 (Figure 1). Among them, four subjects (2.36\%) from the intervention group and 23 subjects from the control group (13.60\%) were dropped out of the trial at the end of twelve intervention months. Six of the 27 subjects in the control group and two of three subjects in the intervention group were HIV-negative due to the error of screening test in the laboratory (Figure 1). Seventeen subjects in the control group and two subjects in the intervention group were dropped out due to a decrease in their CD4 cells count. The distribution of the 27 drop-out according to the cause of drop-out and treatment group is presented in (Figure 1).

Finally for the 142 subjects (84.01\%) who demonstrated the atherogenic lipid abnormalities in HIV-infected antiretroviral-naïve patients were used to continue the study. Demographic characteristics of the 169 HIV-
Infected antiretroviral naïve patients are presented in (Table 3$)$. The results showed that this sample population was made of women $(76.1 \%)$ and men $(23.9 \%)$. The two groups were similar with respect to age, sex. The mean age was $35.6 \pm 9$ years. The value of the BMI decreases none significantly during the twelve months in both groups. The results of clinical characteristics of patients in the spirulina group (Spi) and control show that the presence of sexual transmitted infections (3\%,16\%), malaria $(6 \%, 13 \%)$ and shingles $(3 \%, 7 \%)$. As for lifestyle patients practiced physical activity drank alcohol and tobacco smoke (Table 3). The fasting blood sugar was decreased in the group of patients who add $10 \mathrm{~g}$ of $S$. platensis compare to the other group which in which the variation was no linear. No significant difference was observed in fasting blood sugar in both groups at the first 6 six months. At the end of the study a significant difference was noted in these two groups (Table 3).

\section{Changes in lipid profile and atherogenic index}

To investigate the cardiovascular risk factors of these groups of population, the lipid profile which include the TG, TC, HDL-C, LDL-C and the artherogenic index were determined. 
Table 3 Baseline of demographic and clinical characteristics of patients during the trial

\begin{tabular}{|c|c|c|c|c|c|}
\hline Variables & Ctrl/Spi & Period & Patients received local balance diet & $\begin{array}{l}\text { Patients received spirulina combined } \\
\text { with a local balance diet }\end{array}$ & $p$-value \\
\hline Age (Years) & $87 / 82$ & T0 & $35.43 \pm 10.04$ & $36.01 \pm 9.44$ & 0,58 \\
\hline \multicolumn{6}{|l|}{ Sex (\%) } \\
\hline Female & $87 / 82$ & T0 & $64.5 \%(56)$ & $69.8 \%(60)$ & 0.06 \\
\hline Male & & & $35.6 \%(31)$ & $25.6 \%(22)$ & \\
\hline \multirow[t]{3}{*}{ BMI $\left(\mathrm{kg} / \mathrm{m}^{2}\right)$} & $87 / 82$ & T0 & $26.02 \pm 4.97$ & $25.29 \pm 4.54$ & 0.33 \\
\hline & $79 / 80$ & T6 & $25.18 \pm 6.41$ & $25.41 \pm 4.98$ & 0.80 \\
\hline & $66 / 79$ & $\mathrm{~T} 12$ & $22.18 \pm 1.07$ & $23.26 \pm 6.53$ & 0.44 \\
\hline \multirow[t]{3}{*}{ Fasting blood sugar (mg/l) } & $87 / 82$ & T0 & $115 \pm 53,70$ & $105.89 \pm 25.91$ & 0.159 \\
\hline & $79 / 80$ & T6 & $105.00 \pm 30.76$ & $103.14 \pm 15.93$ & 0.65 \\
\hline & $66 / 79$ & $\mathrm{~T} 12$ & $113.77 \pm 61,85$ & $95.35 \pm 9.63$ & $<0,001$ \\
\hline \multirow[t]{3}{*}{ Alcohol } & $14 / 169$ & To & $11.9 \%$ & $11.9 \%$ & \\
\hline & $10 / 156$ & T6 & $11.9 \%$ & $5.6 \%$ & \\
\hline & $7 / 145$ & $\mathrm{~T} 12$ & $4.4 \%$ & $4.4 \%$ & \\
\hline \multirow[t]{3}{*}{ Smoking } & $5 / 169$ & To & $3 \%$ & $4.5 \%$ & \\
\hline & $5 / 169$ & T6 & $3 \%$ & $4.5 \%$ & \\
\hline & $6 / 169$ & $\mathrm{~T} 12$ & $1.4 \%$ & $3 \%$ & \\
\hline
\end{tabular}

Ctrl: Control, Spi: Spirulina group, T0: initial period, T6: Six months, T12: Twelve months, $\mathrm{p}<0.01$ : Significant difference between the group.

The results showed that the concentration of TG, TC and LDL-C significantly decreased in the Spi group while those of the control group increased (Table 4). This result shows that the consumption of $S$. platensis positively and significantly affects the lipids profile. The Figures 2, 3, 4, 5 and 6 show the variation of lipids profile during the experiment. This results showed that the levels of TG of patient from Spi group, initially higher than those of control group significantly dropped at the end of the intervention (206.89 versus $117.59 \mathrm{p}<0.0001)$ and $(98.90$ versus $162.25 \mathrm{p}<0.0001$ ) (Figure 2 ). In the same population, the levels of HDL-C increased significantly from 48.00 to $100.98 \mathrm{p}=0.71, \mathrm{p}<001, \mathrm{p}<0.0001)$ during the same period of study (Figure 4). The results of atherogenic index defined by the ratio of TC/HDL-C or LDL-C/HDL-C showed these ratio significantly decreased from 10.83 to 2.22 after twelve month $(\mathrm{p}=0.21, \mathrm{p}=0.64, \mathrm{p}<0.0001)$ for (TC/HDL-C) and from 8.24 to $0.96(\mathrm{p}=0.26, \mathrm{p}=0.21$, $\mathrm{p}<0.0001)$ (LDL-C/HDL-C) for patients using S. platensis as supplement while for the control group these the value this ratio increased (Figure 6). These results demonstrated that the supplementation of S. platensis on diet have benefit effect on the lipid profile of HIV patients.

\section{Discussion}

The present randomized control study was designed to compare the effects of consumption of S. platensis on some metabolic parameters among HIV-infected antiretroviral naïve patients. Studies showed that dietary supplements are often used by people living with HIV infection [37].
Previous research also demonstrated similar use, such as a study of HIV positive men that found $69 \%$ used complementary medicine products and practices, the most common of which were dietary supplements [38]. The most common dietary supplements in people living with HIV/ AIDS (PLWH) are used to 'boost immune functioning' such as mega-dose vitamins, and anti-oxidants and body cleansing products such as teas and herbs to remove 'toxins' [39]. It is important to note that while some dietary supplements can adversely interact with prescription medications [40], some supplements may also have positive impacts on HIV disease processes. The supplementation of S. platensis in diet improves the living conditions of HIV patients by providing macronutrients and energy which play an important role on the health of these patients.

The variation of the lipid profile among HIV-infected antiretroviral naïve patients was determined in the study. Dyslipidemia is one of the significant modifiable risk factors for cardiovascular diseases. The dyslipidemia is characterized by a decrease of the levels of high-density lipoproteins cholesterol (HDL-C), an increase of the levels of low-density lipoprotein cholesterol (LDL-C) and elevated levels of triglycerides (TG). In the initial state, our study showed that the level of TC, LDL-C and TG was lower in the control compare to compare to the group of patients supplementing with S. platensis. Our observations are in agreement with previous studies in United States and other parts of sub-Saharan Africa that documented the lipid profile of the treatment-naïve HIV-infected individuals 
Table 4 Change in lipid profile during the six months of intervention and the follow up in each group

\begin{tabular}{|c|c|c|c|c|c|}
\hline Variables & Ctrl/Spi & Period & Patients received local balance diet & $\begin{array}{l}\text { Patients received spirulina combined } \\
\text { with a local balance diet }\end{array}$ & P-value \\
\hline \multirow[t]{3}{*}{ Total cholesterol (mg/dL) } & $87 / 82$ & T0 & $194.8 \pm 80.1$ & $228.7 \pm 96.8$ & 0.17 \\
\hline & $79 / 80$ & T6 & $216.8 \pm 109.4$ & $143.3 \pm 45.4$ & $<0.001$ \\
\hline & $66 / 79$ & $\mathrm{~T} 12$ & $234.9 \pm 101.8$ & $141.4 \pm 40.1$ & $<0001$ \\
\hline \multirow[t]{3}{*}{ HDL cholesterol (mg/dL) } & $87 / 82$ & T0 & $53.6 \pm 18.4$ & $48.0 \pm 21.1$ & 0.71 \\
\hline & $79 / 80$ & T6 & $49.9 \pm 21.6$ & $83.2 \pm 39.7$ & $<0.001$ \\
\hline & $88 / 79$ & $\mathrm{~T} 12$ & $57.3 \pm 27.0$ & $100.9 \pm 28.7$ & $<0.001$ \\
\hline \multirow[t]{3}{*}{ LDL cholesterol (mg/dL) } & $87 / 82$ & TO & $120.12 \pm 75.8$ & $127.0 \pm 92.2$ & 0.60 \\
\hline & $79 / 80$ & T6 & $138.3 \pm 105.8$ & $44.5 \pm 33.0$ & $<0.001$ \\
\hline & $66 / 79$ & $\mathrm{~T} 12$ & $146.3 \pm 97.8$ & $29.3 \pm 16.8$ & $<0.001$ \\
\hline \multirow[t]{3}{*}{ Triglycerides (mg/dL) } & $87 / 82$ & TO & $117.6 \pm 76.8$ & $206.9 \pm 122.7$ & $<0.0001$ \\
\hline & $79 / 80$ & T6 & $150.4 \pm 97.5$ & $139.8 \pm 64.2$ & 0.44 \\
\hline & $66 / 79$ & $\mathrm{~T} 12$ & $167.1 \pm 124.8$ & $123.5 \pm 44.6$ & $<0.01$ \\
\hline \multirow[t]{3}{*}{ CT/HDL (mg/dL) } & $87 / 82$ & TO & $3.6 \pm 4.3$ & $4.7 \pm 4.6$ & 0.21 \\
\hline & $79 / 80$ & T6 & $4.34 \pm 5.1$ & $1.7 \pm 1.1$ & 0.64 \\
\hline & $66 / 79$ & $\mathrm{~T} 12$ & $4.1 \pm 3.0$ & $1.4 \pm 1.4$ & $<0.0001$ \\
\hline \multirow[t]{3}{*}{ LDL/HDL (mg/dL) } & $87 / 82$ & TO & $2.2 \pm 4.1$ & $2.6 \pm 4.3$ & 0.26 \\
\hline & $79 / 80$ & T6 & $2.8 \pm 4.89$ & $0.53 \pm 0.84$ & 0.21 \\
\hline & $66 / 79$ & $\mathrm{~T} 12$ & $2.5 \pm 3.6$ & $0.3 \pm 0.6$ & $<0.0001$ \\
\hline
\end{tabular}

Mean values \pm SD.

Ctrl: Control, Spi: Spirulina group; TC: HDL-C and LDL-C: HDL-C ratios were used to calculate the atherogenicity index. TC, total cholesterol; HDL-C, high-density lipoprotein cholesterol; LDL-C, low-density lipoprotein cholesterol; TG, triglycerides, $\mathrm{P}<0.01$ : Significant difference between the group.

[41-44]. After six months, the levels of TC, LDL-C in the serum were higher in the control group compare to the group of patients supplementing with S. platensis. At the same time, the concentration of HDL-C increased during the same period. The increase of the cholesterol levels, in particular LDL-C, TG and TC in the control group suggest the disturbance in the lipids metabolism which can

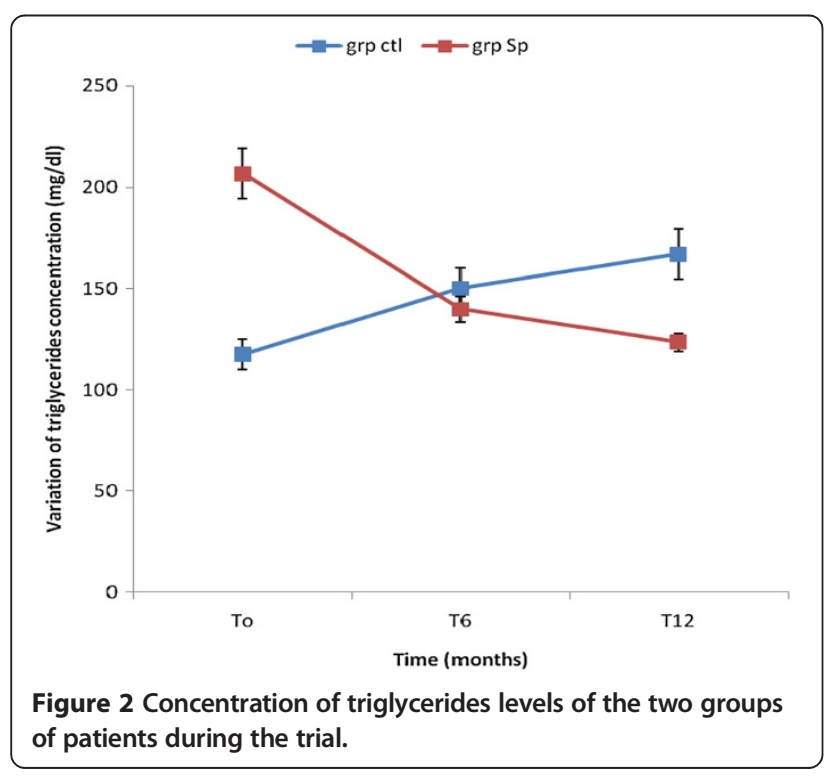

be attributed to the malnutrition [22]. This result demonstrated that $S$. platensis positively and significantly affect the dyslipidemia through the inversion of lipid profile in the group receiving $S$. platensis. The increase TG level in the serum probably caused by an increase of VLDL levels has previously been found to be linked to an increase in

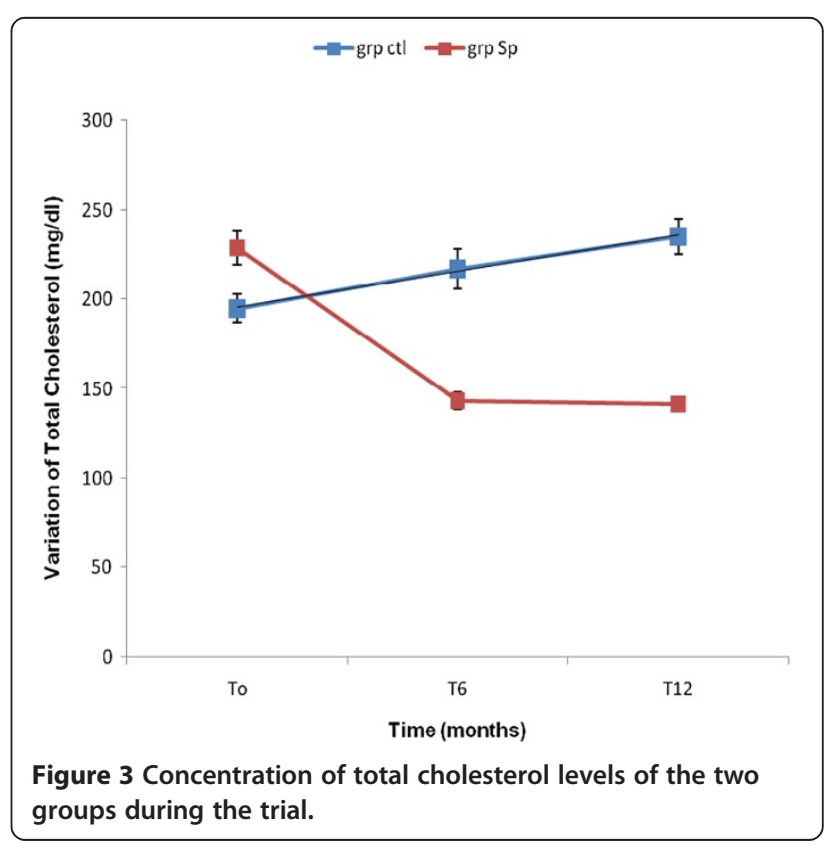




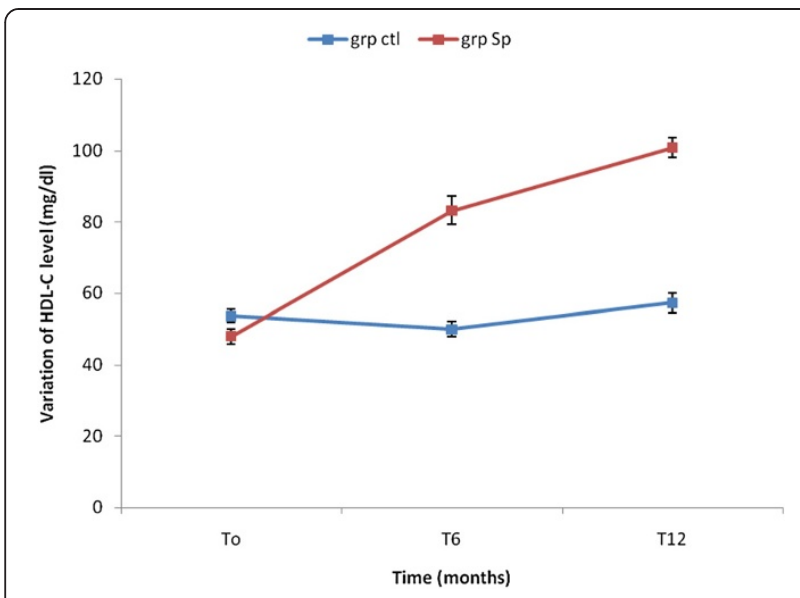

Figure 4 Concentration of HDL-Cholesterol levels of the two groups during the trial.

the synthesis of hepatic fatty acids. In our study, TC was significantly lower in patients who received S. platensis as supplement with a significantly higher concentration of HDL-C in the same group at the end of the trial. The elevation of the HDL-C level occurs before hypertriglyceridemia, correlates with other findings which demonstrated that supplementation of diet with S. platensis decreases LDL-C and increases HDL-C with a probable beneficial effect $[29,30]$. Investigations on the effects of lowering blood cholesterol by S. platensis in rats $[45,46]$ and in different doses (5-16\% of diet) have been published [30]. These studies demonstrated that HIV infection induces an increase of the TG, LDL-C, TC level and the reductions of HDL-C in accordance of other studies $[47,48]$. The observed alteration of cholesterol metabolism in HIV-infected patients may be explained by lipid peroxidation [22,47]. The observed alteration of cholesterol

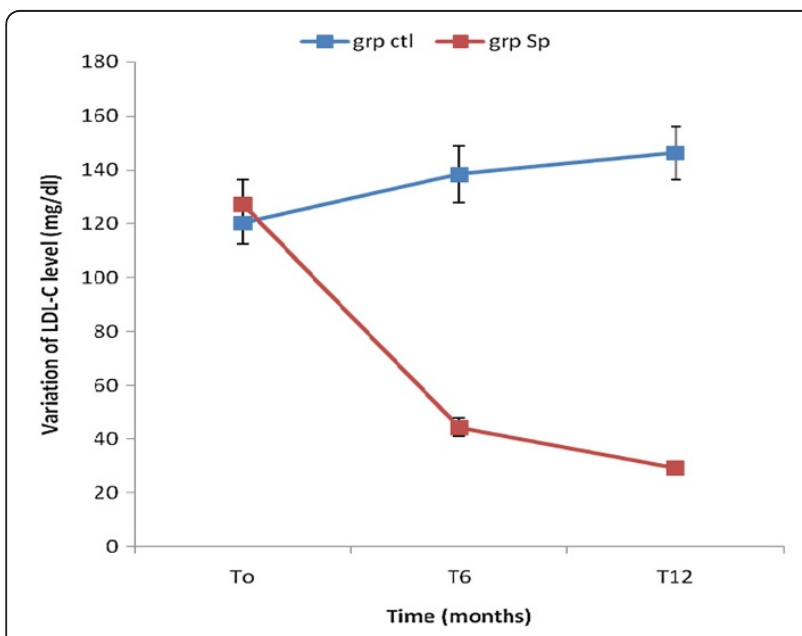

Figure 5 Concentration of LDL cholesterol of the two groups during the trial.

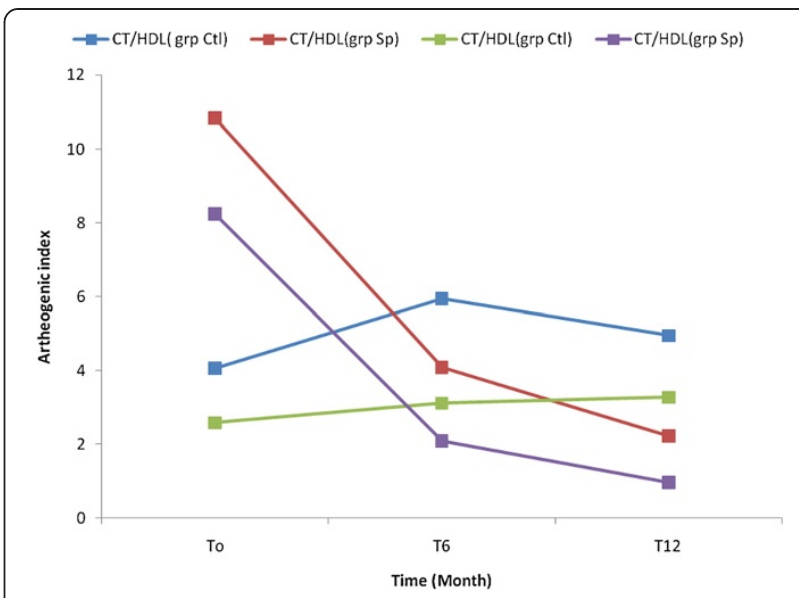

Figure 6 Concentration of artherogenic index of the patients in the two groups during the trial.

metabolism in HIV-infected patients may be explained by the increase of lipid peroxidation through stimulating the production of reactive oxygen species [49]. Other mechanism of lipid disorders in ART-naïve HIV-infected patients is also thought to be cytokine-mediated [44]. A possible relationship between lipids profile and immune system has been noted. Constans et al. [50] reported that HIV infection itself induced a progressive increase in TG and LDL-C. The mechanism used by $S$. platensis to reduce the hypercholesterolemia and lipid disorders have not yet been elucidated although some authors suggest that the addition of this alga into the diet diminishes the intestinal absorption of cholesterol as well as the re-absorption of bile acids in the ileum [51,52]. Thus, they suggest that spirulina can be considered a functional food capable of reducing the levels of cholesterol and consequently preventing atherosclerosis. The antioxidant mechanism of $S$. platensis can also be suggested due to the presence of protein C-phycocyanin, which the structure is closed to that of bilirubin which plays an important physiological role against reactive oxygen species $[31,53]$. This C-phycocyanin protein inhibits oxidative changes in plasma proteins and aromatic amino acid residues [53], increases activity of the enzyme lipoprotein lipase, which is a key enzyme in the metabolism of triglycerides and lipoproteins [54]. These results showed that $S$. platensis demonstrated hypercholesterolemia effects. Although dyslipidemia in HIVinfected patients is believed to carry a similar risk as in HIV-negative populations, the consistent findings of low HDL-C in combination with hypertriglyceridemia can easily increase the burden of cardiovascular diseases in HIV-infected patients by unwanted proportions [55]. This is because hypertriglyceridemia and low HDL-C are recognized independent risk factors for coronary artery disease. Our results demonstrated the reduction of TG, TC and LDL-C to the patient receiving S. platensis. The study 
that the presence of S. platensis reduces the risk of cardiovascular diseases in HIV patients regarding dyslipidemia.

\section{Limitations of the study}

Comprehensive cardiovascular risk factors were assessed in this study. However, the decreased risk of cardiovascular diseases associated with S. platensis intake is well known [15], and long term use of first-line HAART may have an impact on cardiovascular systems, which were not assessed in this study. Others factors not controlled in the analysis were the mechanisms of S. platensis on lipoprotein lipase which may have influenced the decreased of triglycerides.

\section{Conclusion}

The consumption of balance diet combined with S. platensis powder has beneficial effects of lipids profile in the intervention group at the end of the trial. From this, we can assume that a regular consumption of a balanced diet could slow down metabolic disorders of lipids and reinforce the immune defense system in HIV infected antiretroviral naïve patients.

\section{Competing interests}

The authors declare that they have no competing interests.

\section{Authors' contributions}

NMME and AKM conceptualized and designed the study. NMME managed the study and implemented the study protocol. NMME, AKM, PCA and NBPC contributed to the data analyses and to assist in writing early manuscript. PCA, MMB, NG performed laboratory analyses HIV data. NMME and NG conducted interviews, performed quality assurance for interviews data, managed the pill count data and interpreted data. EH oversaw quality assurance. NYJ and MKM oversaw quality assurance and supervised the research. KE and SP partly sponsored a part of the research. All authors read and approved the final manuscript.

\section{Acknowledgements}

We want to acknowledge the laboratory of Biochemistry, Faculty of Medicine and Biomedical Sciences, University of Yaounde 1, for their limitless support during data collection; The Chantal Biya International Research Centre, Yaounde-Cameroon, for materials and reagents support, and the HIV/ AIDS patients for their voluntarily participation in the study. This work was supported by the supplements from the Spirulina producer's Federation of French and Ecole de formation Agricole de Hyères- France.

\section{Author details}

'National Institute of Agro-Industrial Sciences, University of Ngaoundere, POBOX 455, Ngaoundere, Cameroun. ${ }^{2}$ Department of Physiological Sciences and Biochemistry, Faculty of Medicine and Biomedical Sciences, University of Yaounde 1, POBOX 1634, Yaounde, Cameroon. ${ }^{3}$ Charity Health Centre, Berlin, Germany. ${ }^{4}$ Department of Biochemistry, University of Dschang, Dschang, Cameroon. ${ }^{5}$ Spirulina Producer's Federation of France, Hyères, France. ${ }^{6}$ Ecole de formation Agricole de Hyères, Hyères, France.

Received: 11 June 2014 Accepted: 4 December 2014

Published: 13 December 2014

\section{References}

1. Triant VA: HIV infection and coronary heart disease: an intersection of epidemics. J Infec Dis 2012, 205:355-361.

2. Glass TR, Ungsedhapand C, Wolbers M, Weber R, Vernazza PL, Rickenbach M, Furrer H, Bernasconi E, Cavassini M, Hirschel B, Battegay M, Bucher HC, the Swiss HIV Cohort: Study Prevalence of risk factors for cardiovascular disease in HIVinfected patients over time: the Swiss HIV Cohort Study. HIV Med 2006, 7:404-410.

3. Palella FJ Jr, Baker RK, Moorman AC, Chmie JS, Wood KC, Brooks JT, Holmberg SD, HIV Outpatient Study Investigators: Mortality in the highly active antiretroviral therapy era: changing causes of death and disease in the HIV outpatient study. J Acquir Immune Defic Syndr 2006, 43:27-34.

4. Triant VA, Lee H, Hadigan C, Grinspoon SK: Increased acute myocardial infarction rates and cardiovascular risk factors among patients with human immunodeficiency virus disease. J Clin Endo Crinol Metab 2007, 92:2506-2512.

5. Lewden C, May T, Rosenthal E, Burty C, Bonnet F, Costagliola D, Jougla E, Semaille C, Morlat P, Salmon D, Cacoub P, Chêne G, ANRS EN19 Mortalité Study Group and Mortavic: Changes in causes of death among adults infected by HIV between 2000 and 2005: The "Mortalite 2000 and 2005" surveys (ANRS EN19 and Mortavic). J Acquir Immune Defic Syndr 2008, 48:590-598.

6. Boccara F, Lang S, Meuleman C, Ederhy S, Mary-Krause M, Costagliola D, Capeau J, Cohen A: HIV and coronary heart disease time for a better understanding. J Am Coll Card 2013, 61(5):511-523.

7. Joint United Nations Program on HIV/AIDS/World Health Organization (UNAIDS/WHO) Geneva, Switzerland: AIDS Epidemic Update, UNAIDS/WHO, Volume 232. 2009:196-197.

8. El-Sadr WM, Mullin CM, Carr A, Gibert C, Rappoport C, Visnegarwala F, Grunfeld C, Raghavan SS: Effects of HIV disease on lipid, glucose and insulin levels: results from a large antiretroviral-naïve cohort. HIV Med 2005, 6:114-121.

9. Albuquerque Gonçalves VM, Zírpoli JC, de Barros MF D, Albuquerque Mde F, Ulisses RM, de Alencar Ximenes RA, Lacerda HR: Risk factors for subclinical atherosclerosis in HIV-infected patients under and over 40 years: a case-control study. BMC Infec Dis 2013, 13:214.

10. Mbanya JC, Minkoulou E, Salah J, Balkau B: The Prevalence of Hypertension in Rural and Urban Cameroon. Int J Epidemiol 1998, 27(2):181-185.

11. Mbewu A, Mbanya JC: Cardiovascular Disease In Disease and Mortality in Sub-Saharan Africa. 2nd edition. 2006:1-36.

12. Tantchou Tchoumi JC, Butera G: Profile of cardiac disease in Cameroon and impact on health care services. Cardiovasc Diagn Ther 2013, 3(4):236-243.

13. Magula NP, Mayosi BM: Cardiac involvement in HIV-infected people living in Africa: a review. Cardiovasc J S Afr 2003, 14:231-237.

14. Ministry of Public Health and Cameroon National AIDS Control Committee: Preliminary Results of the Demographic and Health Survey (DHS-III). Yaounde- Cameroon: Ministry of Public Health; 2004.

15. HUANG PL: A comprehensive definition for metabolic syndrome. Dis Models Mech 2009, 2:231-237.

16. Pujari SN, Dravid A, Naik E, Bhagat S, Tash K, Nadler JP, Sinnott JT: Lipodystrophy and dyslipidemia among patients taking first-line, World Health Organization-recommended highly active antiretroviral therapy regimens in Western India. J Acquir Immune Defic Syndr 2005, 39(2):199-202

17. Semenkovich CF: Insulin resistance and atherosclerosis. J Clin Invest 2006, 116:1813-1822.

18. Grinspoon SMD, Carr Andrew MD: Cardiovascular risk and body-fat abnormalities in HIV-infected adults. New Engl J Med 2005, 352:48-62.

19. Ramezani A, Mohraz M, Banifazl M, Gachkar L, Jam S, Eslamifar A, Yaghmaie F, Nemati K, Aghakhani A: Metabolic abnormalities in HIV-positive patients receiving highly active antiretroviral therapy. Iranian J Path 2007, 2(3):154-158,

20. Madhu N, Rao MN, Lee GA, Grunfeld C: Metabolic abnormalities associated with the use of protease inhibitors and non-nucleoside reverse transcriptase inhibitors. Am J Infect Dis 2006, 2(3):159-166.

21. Currier JS: Update on cardiovascular complications in HIV infection. Los Angeles USA HIV-MED 2009, 17:98-103.

22. Almeida LB, Degurado AC, Duran AC, Jaime PC: Impact of a nutritional counseling program on prevention of HAART-related metabolic and morphologic abnormalities. AIDS Care 2011, 6(23):755-763.

23. Botros D, Somarriba G, Neri D, Miller Tracie L: Interventions to address chronic disease and HIV: strategies to promote exercise and nutrition among HIV-infected individuals. Curr HIV/AIDS Rep 2012, 9(4):351-363.

24. Azabji-Kenfack M, Loni GE, Sobngwi E, Onana EA, Dikosso ES, Von der Weid D, Gbaguidi E, Ngogang J, Mbanya JC: The effect of Spirulina Platensis versus 
soybean on insulin resistance in HIV-infected patients: a randomized pilot study. Nutrients 2011, 3:712-724

25. Suelen Jorge S, Liania Alves L, Sigrid Sousa S, Carvalho RPH: Lipid profile in highly active antiretroviral therapy-naïve HIV-infected patients in Cameroon: A case-control study. HIV Med 2010, 11:353-359.

26. De Pee S, Semba RD: Role of nutrition in HIV infection: review of evidence for more effective programming in resource-limited settings. Food Nutr Bull 2010, 31(4):313-344.

27. Lecerf J-M, Institut Danone: Les compléments alimentaires: intérêts et limites. 2008. http://www.institutdanone.org/comprendre/publications/objectifnutrition/081/dossier.php.

28. Leonard J, Compere P: Spirulina platensis (Gom.) Geitler, algue bleue de grande valeur alimentaire par sa richesse en proteines. Bull Nat Plantentuin Belg 1967, 37(1):23.

29. Delpeuch F, Joseph A, Cavelier C: Consommation alimentaire et apport nutritionnel des algues bleues (Oscillatoris platensis) chez quelques populations du Kanem (Tchad). Anna Nutr Alim 1975, 29:497-515.

30. Colla LM, Muccillo-Baisch AL, Vieira Costa JA: Spirulina platensis effects on the levels of total cholesterol, $\mathrm{HDL}$ and triacylglycerols in rabbits fed with a hypercholesterolemic diet. Braz Arch Biol Technol 2008, 51(2):405-411.

31. Sun Hee C, Mi Yeon K, Dai-Eun S, Seock-Yeon H, Yin Hee K, Hye Ran K, Jeung Hee L, Jung-Bae K, Mee Ree K: Spirulina prevents Atherosclerosis by reducing Hypercholesterolemia in Rabbits Fed a High- Cholesterol Diet. J Nutr Sci Vitaminol 2010, 56:34-40.

32. Nagaoka S, Shimizu K, Kaneko H, Shibayama F, Morikawa K, Kanamaru Y, Otsuka A, Hirahashi T, Kato T: A novel protein C-phycocyanin plays a crucial role in the hypocholesterolemic action of Spirulina Platensis concentrate in rats. J Nutr 2005, 135:2425-2430.

33. Romay C, Armesto J, Remirez D, Gonzalez R, Ledon N, Garcia I: Antioxidant and anti-inflammatory properties of C-phycocyanin from blue-green algae. Inflam Res 1998, 47(1):36-41.

34. AOAC: Official Methods of Analysis. 15th edition. Washington, DC: Association of Official Analytical Chemist; 1990:2.

35. AFNOR (Association Française de Normalisation): Acides gras et composés lipidiques, Recueil des Normes Françaises. 1981:250.

36. Cerning J, Guilbot J: Change in carbohydrate composition during maturation of wheat and barley kernel. Cereal Chem 1973, 50:220-225.

37. Seth CK, Chauncey C, White D, Jones M, Moira OK, Mervi AD, Angela MC Schinazi RF: Use of dietary supplements among people living with HIV/ AIDS is associated with vulnerability to medical misinformation on the internet. AIDS Res Ther 2012, 9:1. doi:10.1186/1742-6405-9-1.

38. Wolfram G: New reference values for nutrient intake in Germany, Austria and Switzerland (DACH-Reference Values). Forum Nut 2003, 56:95-97.

39. Friedewald WT, Levy RI, Frederickson DS: Estimation of concentration of low-density lipoprotein cholesterol in plasma, without use of the preparative ultracentrifuge. Clin Chem 1972, 18:449-502.

40. National Center for Complementary and Alternative Medicine (NCCAM): Using Dietary Supplements Wisely. 2014. http://nccam.nih.gov/sites/nccam. nih.gov/files/Using_Dietary_Supplements_Wisely_CAM_06-12-2014.

41. Riddler SA, Smit E, Cole SR, Li R, Chmiel JS, Dobs A, Palella F, Visscher B, Evans R, Kingsley LA: Impact of HIV infection and HAART on serum lipids in men. JAMA 2003, 289:2978-2982.

42. Nguemaïm NF, Mbuagbaw J, Nkoa T, Alemnji G, Této G, Fanhi TC, Asonganyi T, Samé-Ekobo A: Serum lipid profile in highly active antiretroviral therapy-naïve HIV-infected patients in Cameroon: A case-control study. HIV Med 2010, 11:353-359.

43. Obirikorang C, Yeboah FA, Quaye L: Serum lipid profiling in highly active antiretroviral therapy-naive HIV positive patients in Ghana: Any potential risk? Webmed Cent Infec Dis 2010, 1(10):1-9.

44. Daniyam CA, Iroezindu MO: Lipid profile of anti-retroviral treatment-naïve HIV-infected patients in jos. Nigeria Ann Med Health Sci Res 2013, 3(1):26-30.

45. Lee JB, Srisomporn P, Hayashi K, Tanaka T, Sankawa U, Hayashi T: Effects of structural modification of calcium spirulan, a sulfated polysaccharide from Spirulina platensis, on antiviral activity. Chem Pharm Bull 2001, 49(1):108-110.

46. Iwata $K$, Inayama $T$, Kato T: Effects of Spirulina platensis on plasma lipoprotein Effects of Spirulina platensis on plasma lipoprotein lipase activity in fructose-induced hyperlipidemic rats. J Nutr Sci Vitaminol 1990, 36(2):165-171

47. Grunfeld C, Pang M, Doerrler W, Shigenaga JK, Jensen P, Feingold KR: Lipids, lipoproteins, triglyceride clearance, and cytokines in human immunodeficiency virus infection and the acquired immunodeficiency Syndrome. J Clin Endocrinol Metab 1992, 74:1045-1052.

48. Lando G, Mbanya D, Magoue C: Lipid abnormalities in HIV/AIDS infected subjects in Cameroon. Yaounde, Cameroon: 4th Congress of the Federation of African Societies of Biochemistry and Molecular Biology; 2001:89 [Abstract].

49. Mc Donagh J, Fossel ET, Kradin RK, Dubinett SM, Laposata M, Hallaq YA: Effect of Tumor Necrosis Factor-a on peroxidation of plasma lipoprotein lipids in experimental animals and patients. Blood 1992, 80:3217-3226.

50. Constans J, Pellegrin JL, Peuchant E, Dumon MF, Pellegrin I, Sergeant C, Simonoff M, Brossard G, Barbeau P, Fleury H: Plasma lipids in HIV-infected patients: a prospective study in 95 patients. Eur J Clin Invest 1994, 24:416-420

51. Cheong SH, Kim MY, Sok DE, Hwang SY, Kim JH, Kim HR, Lee JH, Kim YB, Kim MR: Spirulina prevents atherosclerosis by reducing hypercholesterolemia in rabbits fed a high-cholesterol diet. J Nutr Sci Vitaminol 2010, 56:34-40.

52. Leandro PM, Guilherme MP, Wladimir RB, Inaian PT, Ana Carolina G, Gláucio AS, Maria Alice RM: Exercise and spirulina control non-alcoholic hepatic steatosis and lipid profile in diabetic Wistar rats. Lipids Health Dis 2011, 10:77.

53. Bhat VB, Madyastha KM: Scavenging of Peroxynitrite by Phycocyanin and Phycocyanobilin from Spirulina platensis : Protection against Oxidative Damage to DNA. Biochem BiophysRes Comm 2001, 285:262-266.

54. Belay A: The potentiel application of Spirulina (Arthrospira) as a nutritional and therapeutic supplement in health management. J Am Nutraceut 2002, 5(2):26-49.

55. Dubé MP, Stein JH, Aberg JA, Fichtenbaum CJ, Gerber JG, Tashima KT, Henry WK, Currier JS, Sprecher D, Glesby MJ, Adult AIDS Clinical Trials Group Cardiovascular Subcommittee, HIV Medical Association of the Infectious Disease Society of America: Guidelines for the evaluation and management of dyslipidemia in human immunodeficiency virus (HIV)-infected adults receiving antiretroviral therapy: Recommendations of the HIV Medical Association of the Infectious Disease Society of America and the Adult AIDS Clinical Trials Group. Clin Infect Dis 2003, 37:613-627.

doi:10.1186/1476-511X-13-191

Cite this article as: Ngo-Matip et al.: Effects of Spirulina platensis supplementation on lipid profile in HIV-infected antiretroviral naïve patients in Yaounde - Cameroon: a randomized trial study. Lipids in Health and Disease 2014 13:191.

\section{Submit your next manuscript to BioMed Central and take full advantage of:}

- Convenient online submission

- Thorough peer review

- No space constraints or color figure charges

- Immediate publication on acceptance

- Inclusion in PubMed, CAS, Scopus and Google Scholar

- Research which is freely available for redistribution 